\title{
Endovascular recanalization of superficial femoral artery chronic total occlusions: A multi-disciplinary, single center experience
}

Aparna Swaminathan ${ }^{1}$, Yuliya Lokhnygina ${ }^{2}$, David Kopin ${ }^{1}$, Michael J. Miller ${ }^{3}$, Mitchell W. Cox ${ }^{4}$, James S. Mills ${ }^{1}$, Lawrence Crawford ${ }^{1}$, Manesh R. Patel ${ }^{1,2}$ and W. Schuyler Jones ${ }^{1,2 *}$

${ }^{1}$ Department of Medicine, Duke University Medical Center, Durham, NC, USA

${ }^{2}$ Duke Clinical Research Institute, Duke University Medical Center, Durham, NC, USA

${ }^{3}$ Department of Radiology, Duke University Medical Center, Durham, NC, USA

${ }^{4}$ Division of Vascular Surgery, Duke University Medical Center, Durham, NC, USA

\begin{abstract}
Purpose: The endovascular treatment of CTO in peripheral arteries is common, but little comparative effectiveness data exists to guide clinicians as to which treatment approach is better. We sought to compare procedural outcomes of superficial femoral artery (SFA) chronic total occlusion (CTO) endovascular recanalization using a primary wire approach versus a CTO recanalization device.
\end{abstract}

Methods: We retrospectively identified all patients in an integrated, 3-hospital health system who underwent lower extremity (LE) angiography from $2009-2013$. Chart abstraction and angiogram review were performed to identify those patients with de novo SFA CTO who underwent attempted endovascular revascularization by either primary wire approach or CTO recanalization device. Outcomes measured included acute procedural success, volume of contrast dye, fluoroscopy time, and total procedure time.

Results: A total of 1,611 patients underwent LE angiography during the study period, and 270 patients were included in the final cohort. There was no significant difference in rates of acute procedural success with primary wire approach when compared with CTO recanalization device ( $84.5 \%$ vs. $77.4 \%, \mathrm{p}=0.32)$. In the adjusted analysis, there was significantly less contrast use with the use of CTO recanalization device.

Conclusions: This study suggests that there is limited difference in acute procedural success rates of SFA CTO revascularization with a CTO recanalization device when compared with a primary wire technique. Larger clinical trials are necessary to demonstrate the value of these devices.

\section{Abbreviation}

LE PAD: Lower extremity peripheral artery disease; CTO: Chronic total occlusion; ESRD: End-stage renal disease; ABI: Ankle brachial index ; mL: Milliliters; SFA: Superficial femoral artery

\section{Introduction}

Lower extremity peripheral artery disease (LE PAD) is a prevalent condition that affects over 8 million Americans [1]. In all patients with LE PAD, medical therapy and risk factor modification are recommended to reduce the morbidity and mortality associated with the disease [2]. In patients who have symptoms (e.g. intermittent claudication, critical limb ischemia) despite medical therapy and exercise training (when applicable), revascularization is frequently recommended to improve symptoms $[2,3]$. A common scenario that clinicians face in the endovascular treatment of LE PAD involves chronic total occlusion (CTO) of the femoropopliteal segment, and it is estimated that $50 \%$ of patients who undergo femoropopliteal intervention have CTO [4]. Due to a number of patient, lesion, and anatomic factors, the inability to cross CTOs is a common cause for failure during endovascular treatment $[5,6]$.

The endovascular treatment of peripheral CTOs can be divided into two main strategies: a primary wire approach and utilization of a
CTO recanalization device. The conventional wire technique has many challenging aspects including penetration of the proximal and distal caps of the CTO, avoidance of dissection and embolization, and reentry into the true lumen of the distal vessel after subintimal passage $[6,7]$. Based on a small number of studies, CTO devices are reportedly capable of increasing acute procedural success (defined as the ability to achieve a technically successful improvement in perfusion to a distal extremity as confirmed on angiography) in patients undergoing revascularization of a peripheral CTO [8-12]. However there is a paucity of comparative effectiveness and safety studies [13], and more information is required to determine whether the use of these devices should be widespread or reserved for use in specific situations (e.g. heavy calcification, long lesion length, only if primary wire approach fails).

Correspondence to: W. Schuyler Jones, MD, DUMC, Department of Medicine, Duke University Medical Center, Durham, NC; Duke Clinical Research Institute, Duke University Medical Center, Durham, NCBox 3330, USA, Tel: (919) 668-8917, E-mail: schuyler.jones@dm.duke.edu

Key words: peripheral artery disease, chronic total occlusion, endovascular recanalization, acute procedural success

Received: March 18, 2017; Accepted: April 03, 2017; Published: April 06, 2017 
We aimed to evaluate all patients who underwent attempted endovascular revascularization of femoropopliteal CTO across multiple hospitals and physician practices in a single healthcare system. The primary intent of this study was to measure the acute procedural success of femoropopliteal CTO revascularization with the use of a primary wire approach and CTO recanalization device. In addition, other important factors such as volume of contrast dye, total fluoroscopy time, and total procedure length were analyzed.

\section{Methods}

\section{Cohort identification}

We retrospectively identified all patients who underwent lower extremity angiography from 2009-2013 at a single health system in the United States. We used a web-based query tool providing direct access to patient clinical data, to identify potential subjects. In order to be included in the study, subjects needed to have either an ICD9 procedure code $(00.40-00.48,39.50,39.90)$ or CPT procedure code (2009 - 2010: 35474, 35493 and 2011-2013: 36245-36248, 37224$37227,75630,75710,75716)$ for lower extremity angiography and/or revascularization as well as an ICD-9 diagnosis code for PAD. After an initial data warehouse search, all subjects greater than 18 years of age then underwent chart abstraction and angiogram review to identify those patients with de novo femoropopliteal CTO who underwent attempted endovascular revascularization by either primary wire approach or CTO recanalization device. CTO was defined as $100 \%$ occlusion, with no minimum or maximum length or diameter criteria. Exclusion criteria included recent (less than 30 days) endovascular or surgical revascularization procedure or prior attempted target lesion revascularization. The final cohort was verified with physician case logs to ensure all eligible cases were captured.

\section{Data collection}

The primary outcome of this study, acute procedural success, was defined as successful passage of the wire or recanalization device in the absence of adverse procedural events. This was determined by physician review of all angiographic studies for acute procedural success and chart abstraction for adverse procedural events. Severe complications (e.g. death, major perforation, acute limb ischemia) during the procedure were regarded as a treatment failure. Assignment to each group was dependent on the choice of initial treatment strategy (primary wire approach $v s$. CTO recanalization device) as determined by chart abstraction and angiography review. Crossover from one treatment to another was captured and considered a treatment failure.

Demographics including date of birth, sex, and race were obtained via chart abstraction. The following clinical characteristics were obtained through ICD-9 codes and verified on chart review: hypertension, diabetes, hyperlipidemia, end-stage renal disease (ESRD), coronary artery disease, and congestive heart failure. Smoking status and ankle brachial index (ABI) results within past six months were obtained by chart abstraction. The following procedure characteristics were obtained by review of the procedure note: procedure indication, operator, physician specialty, and procedural complications. The following characteristics were obtained by review of procedure logs: volume of contrast [milliliters $(\mathrm{mL})$ ], fluoroscopy time (minutes), and total procedure length (minutes). The following angiographic characteristics were obtained via physician review of angiographic studies: presence of iliac stenosis, presence of superficial femoral artery (SFA) or popliteal stenosis (other than the target lesion/ $\mathrm{CTO}$ ), number of runoff vessels, lesion length, presence of calcification (mild, moderate or severe), location of CTO (SFA, popliteal, or both), approach (primary wire $v s$. CTO recanalization device), CTO device type (if applicable), use of subintimal approach (and if so use of reentry device), and treatment after CTO passage (e.g. angioplasty alone, stenting, atherectomy).

\section{Statistical analysis}

Statistical methods included descriptive statistics, chi-square test, and odds ratios based on logistic regression models. In terms of the primary objective, we compared acute procedural success rates between wire passage and CTO recanalization device using chi-square test and logistic regression adjusting for the following variables: age, indication for procedure, physician specialty, location of CTO, lesion length, ESRD, and diabetes. We also used chi-square test and logistic regression to compare complication rates between the two groups. Variables included in the logistic regression model included all of the above variables with the addition of treatment type (angioplasty, atherectomy or stenting). To compare contrast use, fluoroscopy time, and procedure length between primary wire approach and CTO recanalization device, we used Wilcoxan rank-sum test and linear regression approach adjusting for the same variables as above.

The 2-sided significance level was 0.05 . We used SAS version 9.2 for all analyses. The institutional review board of the hospital approved the study.

\section{Results}

\section{Patient population/selection}

With the initial database search, we identified a total of 1,611 patients with LE PAD who underwent lower extremity angiography at the three hospitals within the health system from 2009-2013. After abstraction of all charts and review of angiograms, 270 patients with femoropopliteal CTO who underwent attempted endovascular revascularization and met study criteria were identified (Figure 1). Table 1 shows the demographic and clinical characteristics of all patients who underwent SFA CTO recanalization by primary wire approach or CTO recanalization device. The mean age of patients who underwent SFA CTO endovascular recanalization from 2009-2013 was 68 years of age. Over half of the patients were men and nearly $40 \%$ were African American. There were no significant differences between age, race, sex, comorbidities, or tobacco use between patients who underwent attempted endovascular revascularization according to our treatment groups (primary wire approach, CTO recanalization device).

\section{Procedural characteristics}

Table 2 shows the procedural characteristics of attempted endovascular revascularization according to treatment group (primary wire approach or CTO recanalization device). CTO recanalization devices were only used from 2011-2013, while a primary wire approach was utilized during the entire study period. Both the lesion length and location of CTO (SFA, popliteal, or both) were similar across treatment groups. The indication for revascularization was intermittent claudication for $71 \%$ of patients in the device group compared with $54 \%$ of patients in the wire group. In contrast, the indication for revascularization was critical limb ischemia in only $29 \%$ of patients in the device group and $46 \%$ of patients in the wire group. Cardiologists performed about $75 \%$ of all procedures with CTO recanalization devices when compared with only $50 \%$ of procedures by primary wire approach. Vascular surgeons and radiologists each performed about $12.5 \%$ of procedures with the CTO device compared with $25 \%$ of procedures with a wire approach. The most commonly used CTO 
DEDUCE Search: 1,611 patients with LE PAD underwent lower extremity angiograms at Duke University Hospital, Duke Regional Hospital, or Duke Raleigh Hospital from 2009-2013

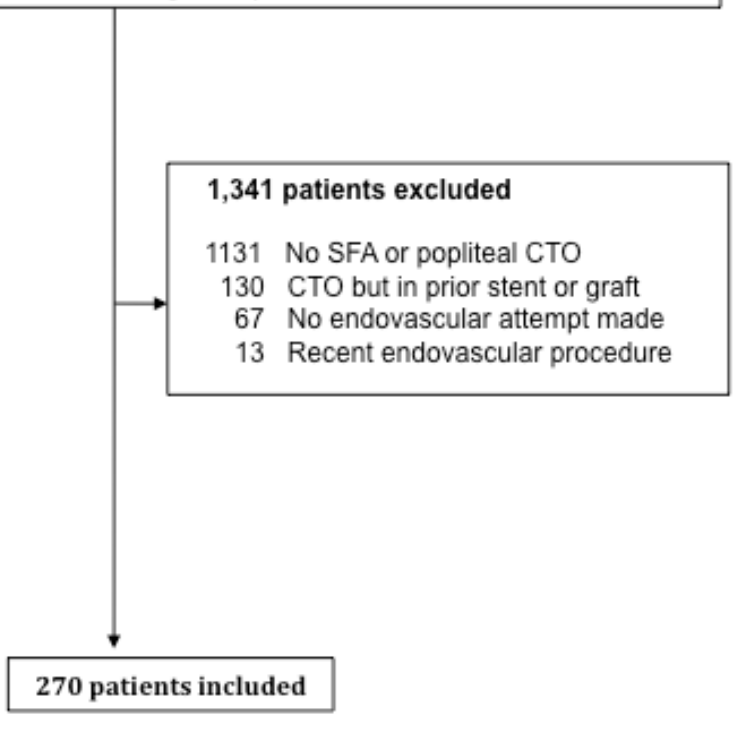

Figure 1. Flow diagram detailing identification and inclusion of patients in the final cohort.

Table 1. Demographic and clinical characteristics.

\begin{tabular}{|c|c|c|c|}
\hline & $\begin{array}{c}\text { Overall } \\
\text { (N= 270) }\end{array}$ & $\begin{array}{c}\text { Primary Wire } \\
\text { Approach } \\
\text { (N= 239) }\end{array}$ & $\begin{array}{c}\text { CTO } \\
\text { recanalization } \\
\text { device (N= 31) }\end{array}$ \\
\hline Age (mean \pm SD), yrs & $68.2 \pm 11.8$ & $68.0 \pm 11.8$ & $70.2 \pm 11.9$ \\
\hline Male (\%) & $58.1 \%$ & $58.6 \%$ & $54.8 \%$ \\
\hline Race (\%) & & & \\
\hline White & $56.3 \%$ & $54.8 \%$ & $67.7 \%$ \\
\hline Black & $39.6 \%$ & $40.6 \%$ & $32.3 \%$ \\
\hline Other & $3.7 \%$ & $4.2 \%$ & $0.0 \%$ \\
\hline Comorbidities: & & & \\
\hline Hypertension (\%) & $94.1 \%$ & $93.3 \%$ & $100.0 \%$ \\
\hline Dyslipidemia (\%) & $84.1 \%$ & $82.8 \%$ & $93.5 \%$ \\
\hline Diabetes Mellitus (\%) & $55.9 \%$ & $55.6 \%$ & $58.1 \%$ \\
\hline End stage renal disease (\%) & $12.2 \%$ & $12.1 \%$ & $12.9 \%$ \\
\hline Coronary artery disease (\%) & $67.0 \%$ & $66.1 \%$ & $74.2 \%$ \\
\hline Congestive heart failure (\%) & $36.7 \%$ & $35.6 \%$ & $45.2 \%$ \\
\hline Current or prior tobacco use (\%) & $74.8 \%$ & $74.0 \%$ & $80.6 \%$ \\
\hline
\end{tabular}

SD: Standard deviation; CTO: Chronic total occlusion

recanalization devices were the Bard Crosser ${ }^{\circledR}$ CTO Recanalization Device $(n=27)$, Boston Scientific True Path ${ }^{\text {Tw }}$ CTO Device $(n=2)$ and Avinger Wildcat ${ }^{\mathrm{tw}}$ catheter $(\mathrm{n}=2)$. Finally, $50 \%$ of patients undergoing procedures using a CTO recanalization device had 3 vessel run off, compared with $25 \%$ of those by primary wire approach.

\section{Procedural outcomes}

There was no significant difference in rates of acute procedural success with primary wire approach when compared with CTO recanalization device $(84.5 \%$ vs. $77.4 \%, \mathrm{p}=0.32$; Table 3$)$. After adjustment, there remained no difference in acute procedural success between treatment groups (Odds Ratio 0.85, 95\% CI $0.33-2.23, \mathrm{p}=$ $0.75)$. In the adjusted analysis, there was significantly less contrast use with CTO recanalization devices $(155.5 \mathrm{~mL}$ vs. $190 \mathrm{~mL}, \mathrm{p}=0.0001)$. There was no significant difference in fluoroscopy time, total procedure length, or complication rate between the primary wire approach and CTO recanalization device groups.

\section{Procedural treatment}

As shown in Table 4, the use of different treatment modalities (angioplasty alone, atherectomy, and stenting) was similar between the primary wire approach and the CTO recanalization device groups. Angioplasty alone was infrequently utilized, and a majority of patients received a stent (either with or without atherectomy use). The use of reentry devices was also similar between the treatment groups (re-entry device use occurred in 11 patients $(4.8 \%)$ in the primary wire approach cohort and 2 patients (6.5\%) in the CTO recanalization device cohort). Complication rates did not significantly differ between treatment groups. Significant complications included three major cardiovascular complications (death, MI), one dissection, two perforations, and five thromboembolic complications.

\section{Discussion}

The primary finding from this retrospective cohort study of endovascular revascularization of femoropopliteal CTO is that there is no difference in the rate of acute procedural success with a primary

Table 2. Procedural data/characteristics.

\begin{tabular}{|c|c|c|c|}
\hline & $\begin{array}{c}\text { Overall } \\
(N=270)\end{array}$ & $\begin{array}{l}\text { Primary } \\
\text { Wire } \\
\text { Approach } \\
(\mathbf{N}=\mathbf{2 3 9})\end{array}$ & $\begin{array}{c}\text { CTO } \\
\text { recanalization } \\
\text { device } \\
(\mathbf{N}=\mathbf{3 1})\end{array}$ \\
\hline \multicolumn{4}{|l|}{ Year of procedure (\%) } \\
\hline 2009 & $21.1 \%$ & $23.8 \%$ & $0.0 \%$ \\
\hline 2010 & $25.6 \%$ & $28.9 \%$ & $0.0 \%$ \\
\hline \multirow[t]{2}{*}{2011} & $21.5 \%$ & $20.5 \%$ & $29.0 \%$ \\
\hline & $18.5 \%$ & $15.9 \%$ & $38.7 \%$ \\
\hline 2013 & $13.3 \%$ & $10.9 \%$ & $32.3 \%$ \\
\hline \multicolumn{4}{|l|}{ Indication for procedure $(\%)$} \\
\hline Intermittent Claudication & $55.9 \%$ & $54.0 \%$ & $71.0 \%$ \\
\hline Critical limb ischemia & $44.1 \%$ & $46.0 \%$ & $29.0 \%$ \\
\hline \multicolumn{4}{|l|}{ Physician specialty (\%) } \\
\hline Cardiology & $55.9 \%$ & $53.6 \%$ & $74.2 \%$ \\
\hline Vascular surgery & $21.9 \%$ & $23.0 \%$ & $12.9 \%$ \\
\hline Radiology & $22.2 \%$ & $23.4 \%$ & $12.9 \%$ \\
\hline \multicolumn{4}{|l|}{ Presence of Iliac Stenosis (\%) } \\
\hline$<50 \%$ & $87.8 \%$ & $87.9 \%$ & $87.1 \%$ \\
\hline $50-99 \%$ & $12.2 \%$ & $12.1 \%$ & $12.9 \%$ \\
\hline \multicolumn{4}{|l|}{$\begin{array}{l}\text { SFA-popliteal stenoses in addition to } \\
\text { CTO }(\%)\end{array}$} \\
\hline No & $61.9 \%$ & $61.1 \%$ & $67.7 \%$ \\
\hline Yes & $38.1 \%$ & $38.9 \%$ & $32.3 \%$ \\
\hline \multicolumn{4}{|l|}{ Number of patent runoff vessels (\%) } \\
\hline 0 & $3.7 \%$ & $4.2 \%$ & $0.0 \%$ \\
\hline 1 & $31.8 \%$ & $32.9 \%$ & $23.3 \%$ \\
\hline 2 & $35.2 \%$ & $36.3 \%$ & $26.7 \%$ \\
\hline 3 & $29.2 \%$ & $26.6 \%$ & $50.0 \%$ \\
\hline Lesion length (mean $\pm \mathrm{SD}), \mathrm{mm}$ & $107.2(84.5)$ & $103.7(83.5)$ & $133.9(88.8)$ \\
\hline \multicolumn{4}{|l|}{ Presence of calcification (\%) } \\
\hline None & $10.8 \%$ & $10.9 \%$ & $9.7 \%$ \\
\hline Mild & $47.2 \%$ & $50.0 \%$ & $25.8 \%$ \\
\hline Moderate & $30.5 \%$ & $27.7 \%$ & $51.6 \%$ \\
\hline Severe & $11.5 \%$ & $11.3 \%$ & $12.9 \%$ \\
\hline \multicolumn{4}{|l|}{ Involvement of CTO overall (\%) } \\
\hline SFA & $73.0 \%$ & $73.2 \%$ & $71.0 \%$ \\
\hline Popliteal & $10.7 \%$ & $10.9 \%$ & $9.7 \%$ \\
\hline SFA + Popliteal & $16.3 \%$ & $15.9 \%$ & $19.4 \%$ \\
\hline
\end{tabular}

SD: Standard deviation; CTO: Chronic total occlusion; SFA: Superficial femoral artery; $\mathrm{mm}$ : millimeter 
Table 3. Procedural outcomes of patients undergoing superficial femoral artery chronic total occlusion recanalization at duke university health system.

\begin{tabular}{|c|c|c|c|c|c|c|}
\hline \multirow[b]{2}{*}{ Outcome } & \multirow[b]{2}{*}{ Primary wire approach } & \multirow{2}{*}{$\begin{array}{c}\text { CTO recanalization } \\
\text { device }\end{array}$} & \multicolumn{2}{|c|}{ Unadjusted analysis } & \multicolumn{2}{|c|}{ Adjusted analysis } \\
\hline & & & $\begin{array}{l}\text { Odds Ratio } \\
(95 \% \text { CI) }\end{array}$ & p-value & $\begin{array}{l}\text { Odds Ratio } \\
\text { (95\% CI) }\end{array}$ & p-value \\
\hline $\begin{array}{l}\text { Acute Procedural } \\
\text { success, } \mathrm{n} / \mathrm{N}(\%)\end{array}$ & $202 / 239(84.5 \%)$ & $24 / 31(77.4 \%)$ & $0.63(0.25,1.56)$ & 0.32 & $0.85(0.33,2.23)$ & 0.75 \\
\hline $\begin{array}{c}\text { Procedural } \\
\text { Complications, } \mathrm{n} / \mathrm{N}(\%)\end{array}$ & $16 / 238(6.7 \%)$ & $2 / 31(6.5 \%)$ & $0.96(0.21,4.38)$ & 0.95 & $0.92(0.16,5.38)$ & 0.92 \\
\hline $\begin{array}{l}\text { Volume of contrast dye, } \\
\text { mL, mean (SD)** }\end{array}$ & $199.0(116.5)$ & $155.5(74.6)$ & - & 0.07 & - & $<0.01$ \\
\hline $\begin{array}{l}\text { Fluoroscopy use, min, } \\
\text { mean (SD)** }\end{array}$ & $37.0(21.5)$ & $36.8(19.5)$ & - & 0.91 & - & 0.10 \\
\hline $\begin{array}{l}\text { Total procedure length, } \\
\text { min, mean }(\mathrm{SD})^{* *}\end{array}$ & $154.4(67.4)$ & $143.2(47.7)$ & - & 0.74 & - & 0.27 \\
\hline
\end{tabular}

CTO: Chronic total occlusion; CI: Confidence interval; $\mathrm{mL}$ : milliliter; min: minute

SD: Standard deviation

Variables included in model: age, indication for procedure, physician specialty, location of stenosis, lesion length, end stage renal disease, diabetes mellitus

** Data was available for 228 and 28 patients for volume of contrast dye, 210 and 27 patients for fluoroscopy time, and 170 and 25 patients for total procedure length for primary wire approach and CTO recanalization device groups, respectively.

Table 4. Procedural treatment of superficial femoral arteries according to treatment modality (angioplasty alone, atherectomy with or without stenting, stenting).

\begin{tabular}{|c|c|c|}
\hline Outcome & $\begin{array}{c}\text { Primary wire approach } \\
\mathbf{N = 2 3 9}\end{array}$ & $\begin{array}{c}\text { CTO recanalization device } \\
\mathbf{N}=\mathbf{3 1}\end{array}$ \\
\hline Angioplasty alone (\%) & $5.5 \%$ & $6.5 \%$ \\
\hline Atherectomy (\%) $*$ & $28.0 \%$ & $29.0 \%$ \\
\hline Stenting (\%) $* *$ & $51.0 \%$ & $41.9 \%$ \\
\hline $\begin{array}{c}\text { Failure to pass wire or CTO } \\
\text { recanalization device (\%) }\end{array}$ & $15.5 \%$ & $22.6 \%$ \\
\hline
\end{tabular}

*Atherectomy group included patients who had angioplasty and/or stenting.

** Stenting group included patients who had angioplasty but not atherectomy.

wire approach when compared with a CTO recanalization device. In the adjusted analysis, there was a lower volume of contrast use in patients treated with CTO recanalization device, but no differences in fluoroscopy time, procedure length, complication rates, or types of treatment devices (including endovascular stents) were observed.

Several small studies have demonstrated high rates of acute procedural success in patients undergoing revascularization with CTO recanalization devices [8-12]. Charalambous, et al. reported a $68 \%$ success rate with Frontrunner ${ }^{\mathrm{TM}}$ catheter in 26 SFA CTOs after guidewire failure [9]. The PATRIOT trial established a $77 \%$ acute procedural success rate with the Crosser ${ }^{\mathrm{TM}}$ recanalization device in 56 patients with lower extremity CTOs [12]. The CONNECT study reported an $89 \%$ success rate for the Wildcat ${ }^{\mathrm{TM}}$ catheter after initial guidewire failure [11]. Finally the ReOpen study also demonstrated an $80 \%$ success rate with the TruePath ${ }^{\mathrm{TM}}$ device in 85 patients with CTOs that failed initial wire passage [8].

The major criticisms of these prior studies include a small sample size, lack of a control arm, and a small group of highly selected operators. The current study has a larger sample size and compared patients who undergo attempted initial endovascular revascularization with either primary wire approach or CTO recanalization device. Another advantage of the current study was inclusion of a broad group of operators from different vascular specialties (interventional cardiology, interventional radiology, vascular surgery). The acute procedural success rate with CTO recanalization devices was similar in our study when compared with other studies. Procedure characteristics such as lesion length, degree of calcification, location of CTO, and indication for revascularization were also similar in our study when compared with previous studies. The main difference between this study and prior observational reports was that the acute procedural success of a primary wire approach was higher in our cohort, thus leading to no difference between groups.

Another major difference between our study and prior studies was the collection of additional procedural variables such as volume of contrast dye, fluoroscopy time, total procedure length, and complication rates. Surprisingly, neither fluoroscopy time nor total procedure length was significantly lower with use of CTO recanalization devices, although the adjusted analysis demonstrated that procedures with the use of CTO recanalization devices were associated with approximately $50 \mathrm{~mL}$ lower volume of contrast use. Similar to many PAD studies, clinical and patient outcomes such as patency rates, repeat revascularization, disease progression, and major adverse cardiovascular events after index revascularization were not available for comparison in our study.

The current findings provide focus for areas of further research, including the need to directly compare the use of CTO recanalization devices to a primary wire approach in the management of lower extremity CTO. Our data does not show a significant difference in acute procedural success rates with these two techniques, a finding that calls into question the utility of these costly devices. Each recanalization device costs approximately $\$ 2,000$ per use and many approved devices require capital purchases for consoles and/or large catheter purchases. While devices (including CTO recanalization devices) undergo a less rigorous approval process through the United States Food and Drug Administration called a 5-10K approval process, more direct comparative trials are required to guide clinicians in the day-to-day use of these devices. Furthermore, it will be imperative to capture clinical outcomes in studies of these high-risk PAD patients to ensure that long-term effectiveness and safety are documented.

The current study has multiple limitations. First, this study was not randomized and despite our adjustment for common clinical and procedural factors, we were not able to eliminate bias (including provider bias in the initial determination of the use a primary wire approach versus CTO recanalization device). Second, while the sample size was larger than previous studies, treatment groups were unequal and small in size, and this may not have permitted us to detect a difference between primary wire approach and CTO recanalization device. Finally, similar to prior studies of CTO recanalization devices, this study lacked long-term clinical outcomes, which are arguably as important in evaluating these devices as acute procedural success. 


\section{Conclusion}

In conclusion, despite a small sample size, there was no difference in rates of acute procedural success of endovascular recanalization of CTO using a primary wire approach when compared with the use of a CTO recanalization device. Future studies should aim to assess longterm clinical effectiveness and safety of these devices when compared with a primary guidewire approach.

\section{External funding}

Funding for this scientific analysis was provided via the Boston Scientific-Duke Strategic Alliance for Research (BD-STAR). Principal Investigator: W. Schuyler Jones, MD.

\section{Prior presentation}

Abstract Poster Presentation, American College of Cardiology, March 2015, San Diego, California, USA.

\section{Authorship declaration}

i) All authors listed meet the authorship criteria according to the latest guidelines of the International Committee of Medical Journal Editors, and ii) All authors are in agreement with the manuscript.

\section{References}

1. Hirsch AT, Haskal ZJ, Hertzer NR, Bakal CW, Creager MA, Halperin JL, et al (2006) ACC/AHA 2005 Practice Guidelines for the management of patients with peripheral arterial disease (lower extremity, renal, mesenteric, and abdominal aortic): a collaborative report from the American Association for Vascular Surgery/Society for Vascular Surgery, Society for Cardiovascular Angiography and Interventions, Society for Vascular Medicine and Biology, Society of Interventional Radiology, and the ACC/ AHA Task Force on Practice Guidelines (Writing Committee to Develop Guidelines for the Management of Patients With Peripheral Arterial Disease): endorsed by the American Association of Cardiovascular and Pulmonary Rehabilitation; National Heart, Lung, and Blood Institute; Society for Vascular Nursing; TransAtlantic Inter-Society Consensus; and Vascular Disease Foundation. Circulation 113:e463-654. [Crossref]

2. Rooke TW, Hirsch AT, Misra S, Sidawy AN, Beckman JA, Findeiss LK, et al. (2011) 2011 ACCF/AHA Focused Update of the Guideline for the Management of Patients With Peripheral Artery Disease (updating the 2005 guideline): a report of the American College of Cardiology Foundation/American Heart Association Task Force on Practice Guidelines. J Am Coll Cardiol 58:2020-2045. [Crossref]
3. Jaff MR, Cahill KE, Yu AP, Birnbaum HG, Engelhart LM (2010) Clinical outcomes and medical care costs among medicare beneficiaries receiving therapy for peripheral arterial disease. Ann Vasc Surg 24:577-587. [Crossref]

4. Banerjee S1, Brilakis ES, Das TS, Lichtenwalter CS (2009) Treatment of complex superficial femoral artery lesions with PolarCathcryoplasty. Am J Cardiol 104:447449. [Crossref]

5. Lee HJ, Park SW, Chang IS,Jeon HJ, Park JH (2012) Strategies for successful revascularization of chronic total occlusion for the femoropopliteal arteries when the antegrade passage of a guide wire fails. Korean J Radiol 13:467-475. [Crossref]

6. Kandzari DE (2004)The challenges of chronic total coronary occlusions: an old problem in a new perspective. J Intervent Cardiol 17:259-267. [Crossref]

7. Mossop P, Amukotuwa SA, Whitbourn RJ (2006) Controlled blunt microdissection for percutaneous recanalization of lower limb arterial chronic total occlusions: a single center experience. Catheter Cardiovasc Interv 68:304-310. [Crossref]

8. Bosiers M, Diaz-Cartelle J, Scheinert D, Peeters P, Dawkins KD(2014) Revascularization of lower extremity chronic total occlusions with a novel intraluminal recanalization device: results of the ReOpen study. J Endovasc Ther 21:61-70. [Crossref]

9. Charalambous N1, Schäfer PJ, Trentmann J, Hümme TH, Stöhring C, Müller-Hülsbeck $\mathrm{S}$, et al. (2010)Percutaneous intraluminal recanalization of long, chronic superficial femoral and popliteal occlusions using the Frontrunner XP CTO device: a single-center experience. Cardiovasc Intervent Radiol 33:25-33. [Crossref]

10. Shetty R, Vivek G, Thakkar A, Prasad R, Pai U, Nayak K (2013) Safety and efficacy of the Frontrunner XP Catheter for recanalization of chronic total occlusion of the femoropopliteal arteries. J Invasive Cardiol 25:344-347. [Crossref]

11. Pigott JP, Raja ML, Davis T, Connect Trial I (2012) A multicenter experience evaluating chronic total occlusion crossing with the Wildcat catheter (the CONNECT study). $J$ Vasc Surg 56:1615-1621. [Crossref]

12. Staniloae CS1, Mody KP, Yadav SS, Han SY, Korabathina R (2011)Endolumina treatment of peripheral chronic total occlusions using the $\operatorname{Crosser}(\mathrm{R})$ recanalization catheter. J Invasive Cardiol 23:359-362. [Crossref]

13. Jones WS, Schmit KM, Vemulapalli S, Subherwal S, Patel MR, Hasselblad V, et al (2013) Treatment strategies for patients with peripheral artery disease. Comparative Effectiveness Review No. 118. (Prepared by the Duke Evidence-based Practice Center under Contract No. 290-2007-10066-I.) AHRQ Publication No. 13-EHC090-EF. Rockville, MD: Agency for Healthcare Research and Quality. [Crossref]

Copyright: (C2017 Swaminathan A. This is an open-access article distributed under the terms of the Creative Commons Attribution License, which permits unrestricted use, distribution, and reproduction in any medium, provided the original author and source are credited. 